\title{
Persistence of phylogeographic footprints helps to understand cryptic diversity detected in two marine amphipods widespread in the Mediterranean basin
}

\author{
Hupało, K. ${ }^{\text {A }}$, Teixeira, M.A.L. ${ }^{\mathrm{B}}$, Rewicz, T. ${ }^{\mathrm{A}}$, Sezgin M. ${ }^{\mathrm{C}}$, Iannilli V. ${ }^{\mathrm{D}}$, Karaman G.S. ${ }^{\mathrm{E}}$, \\ Grabowski M. ${ }^{\mathrm{A}}$, Costa, F.O. ${ }^{\mathrm{B}}$ \\ ${ }^{A}$ Department of Invertebrate Zoology and Hydrobiology, University of Lodz, Banacha 12/16, 90-237 Łódź, Poland \\ ${ }^{\mathrm{B} C e n t r e ~ o f ~ M o l e c u l a r ~ a n d ~ E n v i r o n m e n t a l ~ B i o l o g y ~(C B M A), ~ D e p a r t m e n t ~ o f ~ B i o l o g y, ~ U n i v e r s i t y ~ o f ~ M i n h o, ~ B r a g a, ~}$ \\ Portugal \\ ${ }^{C}$ Sinop University Fisheries Faculty, Marine Biology and Ecology Department, Sinop, Turkey \\ DENEA C.R. Casaccia, via Anguillarese 301, 00123 Rome, Italy \\ EMontegrin Academy of Sciences and Arts, Riste Stijovica Podgorica Črna Gora, Montenegro
}

Corresponding author: Kamil Hupało (e-mail: kamilhupalo@gmail.com)

\begin{abstract}
Amphipods of the genus Gammarus are a vital component of macrozoobenthic communities in European inland and coastal, marine and brackish waters of the Mediterranean and the Black Sea. Exceptional levels of cryptic diversity have been revealed for several widespread freshwater Gammarus species in Europe. No comprehensive assessment has yet been made for brackishwater counterparts, such as Gammarus aequicauda and G. insensibilis, which are among the most widely dispersed members of the so-called "G. locusta group" in the Mediterranean and in the Black Sea. Here we probe the diversity of these morphospecies examining the partitioning of mtDNA and nDNA across multiple populations along their distribution range and discuss it within the regional paleogeographic framework.
\end{abstract}

We gathered molecular data from a collection of 166 individuals of G. aequicauda and G. insensibilis from 47 locations along their distribution range in the Mediterranean including the Black Sea. They were amplified for both mitochondrial COI and 16S rRNA as well as the nuclear 28S rRNA. All five MOTU delimitation methods applied revealed deep divergence between Black Sea and Mediterranean populations in both G. aequicauda and G. insensibilis. There were eight distinct MOTUs delimited for G. aequicauda (6-18\% K2P) and 4 MOTUs for G. insensibilis (4-14\% K2P). No sympatric MOTUs were detected throughout their distribution range. Multimarker time-calibrated phylogeny indicated that divergence of both $G$. aequicauda and G. insensibilis species complexes started already in the late Oligocene/early Miocene with the split between clades inhabiting eastern and western part of the Mediterranean occurring in both species at the similar time.

Our results indicate a high cryptic diversity within Mediterranean brackishwater Gammarus, similar to that observed for freshwater counterparts. Moreover, the phylogenetic history combined with the current geographic distribution indicate that the evolution of both studied Gammarus morphogroups has been strongly connected with the geological events in the 
Mediterranean Basin and it reflect the turbulent history of the area. The results also point out the possibility of the existence of monopolization and yet unknown biogeographical barriers in the Mediterranean that might inhibit the sympatry and the dispersal of the existing lineages.

Keywords: marine, Gammarus, Amphipoda, phylogeography, cryptic diversity

Declarations of interest: none 


\section{Introduction}

Amphipods of the genus Gammarus are a salient component of marine and brackishwater coastal ecosystems of the North Atlantic, Mediterranean and adjacent seas. They are among the most prominent macroinvertebrates in many locations (e.g. Costa and Costa, 1999; Kevrekidis et al., 2009; Prato and Biandolino, 2003), and play a key role in trophic chains, as grazers, scavengers and as prey for other macroinvertebrates, fish and seabirds (e.g. Casagranda et al., 2006; Macneil et al, 1999; Ryer, 1988; Thiel and Reise, 1993; Verkuil et al., 1993). Due to their widespread distribution, significance in the food web, and sensitivity to a wide range of pollutants, members of this group are commonly used as bioindicators (Gerhardt et al, 2011; Neuparth et al., 2005; Remy et al., 2015; ) and assay organisms in ecotoxicological tests (e.g. Costa et al., 1998, 2005; Prato and Biandolino, 2005, 2006).

A major update of the taxonomic status of the European marine Gammarus provided in the mid-20 $0^{\text {th }}$ century (Segerstråle, 1947; Spooner, 1947; Kinne, 1954) resulted in confirmation of the species rank for a set of species restricted to the Northern Atlantic and adjacent seas, such as Gammarus oceanicus Segerstråle, 1947; Gammarus salinus Spooner, 1947 and Gammarus zaddachi Sexton 1912. However, no update of the Mediterranean and the Black Sea species of the so-called G. locusta-group was available until the publication of a comprehensive review by Stock (1967). This publication revealed four new species from this group (Gammarus crinicornis Stock, 1966; Gammarus inaequicauda Stock, 1966; Gammarus insensibilis Stock, 1966; Gammarus subtypicus Stock, 1966), and included an identification key for a total of seven species: the four already mentioned, plus Gammarus aequicauda (Martynov, 1931), Gammarus locusta (Linnaeus, 1758) and Gammarus plumicornis (Costa, 1853). Subsequently, experimental studies on the hybridization between G. aequicauda and G. plumicornis, demonstrated no reproductive barrier and, hence, conspecificity of the two taxa. However, they can be recognized as two distinct morphotypes, that seldomly hybridize in the natural environment, probably due to their different ecological preferences (Stock, 1969). Eventually, the name Gammarus plumicornis was suppressed and the name G. aequicauda was accepted by the International Commission for the Zoological Nomenclature (ICZN) as valid for the species (Stock, 1970; ICZN, 1973). The taxonomic status of Mediterranean marine Gammarus has remained unchanged since then, despite the discovery of intraspecific morphological variants and possible existence of further undescribed within the species complex (Stock, 1967). 
In spite of the extensive and authoritative review, and the availability of a dedicated taxonomic identification key (Stock, 1967), the morphology-based identification of species from this complex group remained challenging for non-experts and untrained researchers, leading to doubtful records and reports in the literature. For example, although Stock's review clearly states that G. locusta is absent from the Mediterranean Sea, various records of that species could still be found decades after (see Costa and Costa, 2000). Gammarus aequicauda and G. insensibilis are among the most frequently recorded species of the locusta group in the Mediterranean and Black Seas (e.g., Myers, 1982). Gammarus insensibilis occurs in both marine and brackish water habitats (Janssen et al., 1979). It tolerates reduced salinity and can be locally abundant in brackish pools and saline lagoons (Lincoln, 1979; Gillil and Sanderson, 2000). Gammarus aequicauda occurs predominantly in brackishwater, particularly oligohaline, habitats, but is locally found also in hyperhaline lagoons and frequently displays high abundances in habitats isolated from the sea. This species is also an important prey for birds and fishes (Kevrekidis and Koukouras 1988). Both species can occur in sympatry (Janssen et al, 1979).

The first attempts to discriminate species in this group with molecular approach used randomly amplified polymorphic DNA (RAPD; Costa et al., 2004). These early trials were largely superseded in accuracy, feasibility and scope with the introduction of DNA barcoding as a universal approach to species identification (Hebert et al., 2003). Indeed, a later study (Costa et al., 2009) used DNA barcodes (i.e. a 658 base pair fragment of the 5' end of the mtDNA-encoded gene cytochrome oxidase subunit I (COI-5P) to probe the taxonomic status of marine Gammarus, including some species of the locusta-group (sensu Stock, 1967). The existence of deep divergences between Black Sea and the conspecific populations from the Mediterranean and Atlantic, was patent in both G. aequicauda and G. insensibilis, but too few populations and specimens were examined to enable more substantial conclusions.

Multiple recent studies upon freshwater Gammarus in Europe (e.g. Mamos et al., 2014, 2016; Weiss et al., 2014; Copilaş-Ciocianu and Petrusek 2015, 2017; Grabowski et al., 2017; Copilaş-Ciocianu et al., 2017) and in other regions (Katouzian et al., 2016) have detected exceptionally high levels of spatial genetic structure and cryptic diversity, both around the Mediterranean (Hou et al., 2011; Wysocka et al., 2014; Mamos et al., 2016) and even on the Mediterranean islands (Hupało et al., unpublished results). Although the extent of the discovered crypticism is noteworthy, it would not have been 
completely unexpected in habitats prone to isolation, allopatry and event-rich geological and climatic history (Griffiths et al., 2004; Popov et al., 2004; Nisancioglu 2010). On the contrary, the marine environment has been perceived as a continuous habitat with low spatial complexity, therefore lowering the expectancy of occurrence of genetic structure in marine populations (see the review by Selkoe et al., 2016). Only recently this perspective started to change with a deeper appreciation of the heterogeneity and spatial complexity of the marine environment (Selkoe et al., 2016). Reports of deep genetic structure and cryptic diversity in the marine environment have been accumulating, with various examples comprising a taxonomically diverse set of marine amphipods from several regions of the globe (Radulovici et al., 2009; Havermans et al., 2011; Knox et al., 2011; Lörz et al. 2011; Cabezas et al., 2013; Yang et al., 2013; Raupach et al., 2015; Lobo et al., 2017)

Here we probe the intraspecific diversity of G. aequicauda and G. insensibilis through the examination of COI-5P barcodes across multiple populations from the Black and Azov Seas, through the Mediterranean and up to the eastern Atlantic Ocean. Given the previous casual findings, the lessons from the local freshwater ecosystems and the turbulent geological history of the Mediterranean region, we hypothesise that both species may be a complex of divergent phylogenetic lineages inhabiting various regions of the studied area. We test this hypothesis by a set of analyses of the polymorphism of two mitochondrial (COI and 16S rDNA), and one nuclear (28S rDNA) molecular markers. By this, we provide the first insight into the phylogeography of these significant species of the Mediterranean shallow water, coastal communities, and convey an interpretation of their molecular diversity patterns within the regional geodynamics framework .

\section{Materials and methods}

\subsection{Sample collection and identification}

The study material was collected from 47 sampling sites, mainly from brackish and marine habitats, visited during several sampling campaigns held from 2001 to 2016 (Fig.1). Individuals of Gammarus were sampled using different methods, including from macroalgae collected in the intertidal area or using rectangular kick sample nets (aperture $25 \times 25 \mathrm{~cm}$ and $0.5 \mathrm{~mm}$ mesh size). The samples were sorted at the site and amphipods were immediately fixed in $96 \%$ ethanol. Afterwards, the material was 
examined under a Nikon 800 stereomicroscope. Identification to species was done according to the diagnostic morphological characters provided by Stock (1967) and using the taxonomic key to the amphipods of the Mediterranean (Bellan-Santini et al., 1982).

\subsection{DNA extraction, PCR amplification, sequencing}

Since our molecular data was produced from merged data sets originated from the University of Lodz (UL) and the University of Minho (UM), two protocols were used, as described by Hupało et al. (2018) and Lobo et al. (2017), respectively. In UL, about $3 \mathrm{~mm}^{3}$ of the muscle tissue was taken out with a sharp-edged forceps from selected individuals and incubated overnight at $55^{\circ} \mathrm{C}$ in $200 \mu \mathrm{l}$ of Queen's lysis buffer with $5 \mu 1$ of proteinase K (20 mg ml-1) (Seutin et al., 1991). Total DNA has been extracted using standard phenol/chlorophorm method, elution volume $=100 \mu \mathrm{L}$ TE buffer, $\mathrm{pH}$ 8.00, (Hillis et al., 1996). In UM, the DNA has been extracted from each individual using the E.Z.N.A Mollusc DNA Kit (Omega Biotek), elution volume $=50 \mu \mathrm{L}, \mathrm{pH} 8.00$, following the manufacturer's instructions. In both cases, the eluted DNA was stored at $4^{\circ} \mathrm{C}$ until amplification and finally long-term stored at $-20^{\circ} \mathrm{C}$. Subsequently, a fragment of the cytochrome c oxidase subunit I gene (COI) was amplified employing different primer pairs depending on amplification success. The primer sequences, PCR cycling conditions and original references for all the molecular markers used in this study are listed in Table S1. PCR products $(5 \mu 1)$ were cleaned up by exonuclease I ( $2 \mathrm{U}$, ThermoFisher) and alkaline phosphatase FastAP (1 U, ThermoFisher) treatment according to the manufacturer's guidelines, and sequenced directly using the same primers as at the amplification stage. Sequencing of the PCR products was performed using BigDye terminator technology by Macrogen Inc.

Subsequently, at least one individual per delimited Molecular Operational Taxonomic Unit (MOTU) (see below) was amplified for additional markers for phylogeny reconstruction - mitochondrial 16S rRNA and a nuclear marker being 28S rRNA gene. The nuclear locus was sequenced in both directions.

\subsection{Sequence data authentication, editing, alignment and deposition}

All resulting sequences were positively verified as Gammarus DNA via BLASTn searches in GenBank (Altschul et al., 1990) and then assembled, aligned and trimmed to $530 \mathrm{bp}$ nucleotides in Geneious 10.0.9 software package (Biomatters Inc, 2017. The 
alignment was performed using MAFFT plugin with G-INS-i algorithm in Geneious. Haplotypes were identified for each marker with the DnaSP software (Librado and Rozas, 2009). All COI sequences of G. aequicauda and G. insensibilis were deposited in GenBank (accession numbers to be provided upon acceptance). Additional COI sequences of $G$. aequicauda and $G$. insensibilis available from the GenBank repository were added to the final alignment, as well as sequences of two individuals of G. locusta to serve as an outgroup in the phylogenetic analyses. All the sequences used in this study were compiled in the dataset DS-AEQINS (DOI to be provided upon acceptance) deposited in the Barcode of Life Data Systems (BOLD; Ratnasingham, and Hebert, 2007), where all the relevant metadata information and sequence trace files are accessible.

To enable direct comparison with other studies, we calculated genetic distances for COI data using the Kimura 2-parameter (K2p) distance (e.g., between all haplotypes, or within and among MOTUs) using MEGA 7.0 (Kumar et al., 2016). Standard error estimates were obtained by a bootstrap procedure (1,000 replicates).

\subsection{MOTU delimitation - cryptic diversity}

We employed five methods and two different approaches to delimit Molecular Operational Taxonomic Units (MOTUs), serving as neutral species equivalents free from conceptual issues, based on the COI sequence data: the distance-based approach, applying the Barcode Index Number (BIN) system (Ratnasingham and Hebert, 2013), and the ABGD software (Puillandre et al., 2012), and the tree-based, phylogenetic approach using two GMYC model-based methods (Pons et al., 2006) according to Monaghan et al. (2009), as well as the bPTP implementation described by Zhang et al. (2013).

The BIN method is a distance-based approach embedded in BOLD. All compliant sequences deposited in BOLD database are clustered according to their molecular divergence, employing algorithms which identify discontinuities between the clusters. A unique and specific Barcode Index Number (BIN) is assigned to each cluster. If newly submitted sequences do not group together with established BINs, a new one is created.

The ABGD method uses pairwise distance measures. ABGD clusters the sequences into MOTUs, in such a way that the genetic distance between two sequences belonging to two separate groups will always be greater than an indicated threshold (i.e. barcode 
gap). In our study, the primary partitions were used as a prime for cluster delimitation, as they tend to remain stable on a wider range of prior values, minimizing the oversplitting of the number of groups. The primary partitions are usually the closest to the number of taxa described by taxonomists (Puillandre et al., 2012). The default value of 0.001 was applied as the minimum intraspecific distance. As the maximum intraspecific distance we investigated a set of values up to 0.03 , which has been empirically employed as an indicative maximum intraspecific distance value for marine amphipods (Costa et al., 2007). The standard Kimura two-parameter (K2p) model correction was used (Hebert et al., 2003).

The GMYC method identifies the transition from intraspecific branching patterns (coalescent) to typical interspecific branching patterns (Yule processes) on an ultrametric, phylogenetic tree, using the maximum likelihood approach. The estimation of the boundary between coalescent and Yule branching processes can be done using two different GMYC approaches, one using the single threshold and the second one based on multiple threshold model. We have reconstructed an ultrametric tree, which is required for these analyses, in BEAST software, using a $20 \mathrm{M}$ iterations long MCMC chain, with $\mathrm{TN} 93+\mathrm{I}+\mathrm{G}$ as the best-fit substitution model. The consensus tree was analysed in the GMYC web server (available at: http://species.h-its.org/gmyc/) using both the single and multiple threshold models.

The bPTP approach for species delimitation is a tree based method which uses nonultrametric phylogenies. This method assumes that the probability that a substitution leads to a speciation event follows a Poisson distribution. In bPTP, the Bayesian support values are added for each delimited cluster (Zhang et al., 2013). For input tree we used a Bayesian inference phylogeny generated through a MrBayes plugin implemented in Geneious software package (Kearse et al., 2012) and employing a $1 \mathrm{M}$ iterations long MCMC chain, sampled every 2,000 iterations. We choose TN93+I+G (Tamura and Nei, 1993) as the best-fit substitution model using bModel test (Bouckaert and Drummond, 2017). The consensus tree was constructed after removal of $25 \%$ of the sampled trees during the burn-in phase. The analysis itself was performed on the bPTP web server (http://www.species.h-its.org/ptp/) applying 500,000 MCMC iterations and a $10 \%$ burn-in.

\subsection{Within MOTU diversity, divergence and historical demography.}


Molecular genetic diversity, divergence and historical demography based on mtDNA COI sequences were, wherever possible, estimated for each MOTU. The phylogenetic relationships between haplotypes within each morphospecies were visualised as a phylogenetic network computed with the neighbour-net algorithm and uncorrected pdistances using the SplitsTree4 software (Huson and Bryant, 2006), whereas the relationships within particular MOTUs were displayed through a Minimum Spanning Network using PopART (Leigh and Bryant, 2015). We estimated the genetic diversity as the number of haplotypes (k), haplotypic diversity (h) and nucleotide diversity $(\pi)$ (Nei, 1987) using the DnaSP6 software (Librado and Rozas, 2009). Molecular divergences were determined as average K2p distance between haplotypes using MEGA 7.0 (Kumar et al., 2016). We examined the historical demographic expansion within MOTUs in Arlequin 3.5.1.3 (Excoffier and Lischer, 2010) using two models of population expansion, demographic and spatial, in mismatch distribution analysis (Slatkin and Hudson, 1991; Rogers and Harpending, 1992), supplemented by Tajima's D (Tajima, 1989) and Fu's Fs (Fu, 1996) neutrality tests with 1,000 replicates. To provide insights into historical demography, i.e., the temporal changes of the effective population size of examined species in the studied region, we performed a Bayesian Skyline Plot (BSP) analysis (Drummond et al., 2005) in BEAST, version 1.8.1 (Drummond et al., 2012) for MOTUs which displayed clear signs of expansion (see Results). The MOTU3 of G. aequicauda was represented by 67 individuals from 19 localities, whereas MOTU3 of $G$. insensibilis was represented by 23 individuals from 3 localities and MOTU4 of G. insensibilis was represented by 8 individuals from 4 localities. The TN93+G model of evolution was used as the best fitting model. We performed three MCMC runs of $50 \mathrm{M}$ iterations, with sampling every 1000 iterations. MCMC runs were examined using Tracer v1.5 (Drummond et al., 2012) and all sampled parameters achieved sufficient effective sample sizes (ESS $>200)$.

\subsection{Time calibration and phylogeny reconstruction}

The time-calibrated phylogeny was reconstructed in BEAST2 software package (Bouckaert et al., 2014) based on data from sequences of COI (509 bp), 16S rRNA (344 bp) and 28S rRNA (1251 bp), employing five MCMC chains of $20 \mathrm{M}$ iterations for each morphospecies and the following best-fit models of substitution: $\mathrm{TN} 93+\mathrm{I}+\mathrm{G}$ (for $\mathrm{COI}$ ), $\mathrm{HKY}+\mathrm{I}+\mathrm{G}$ (for 16S) and $\mathrm{TN} 93+\mathrm{I}+\mathrm{G}$ (for 28S) for G. aequicauda and $\mathrm{HKY}+\mathrm{I}+\mathrm{G}$ (for COI), TN93+I+G (for 16S) and TN93 (for 28S) for G. insensibilis. The best-fit 
models for each marker were selected according to bModel test (Bouckaert and Drummond, 2017). We used a strict clock model for COI based on the published rate of 0.0115 substitutions per million years (Brower 1994). All other clock rates were set on estimate. The resulting trees were checked for ESS values in Tracer and the three trees with the best ESS values were combined in LogCombiner and annotated in TreeAnnotator. The final output tree was edited in FigTree software (http://tree.bio.ed.ac.uk/software/figtree/).

\section{Results}

\subsection{Species geographic distribution and associated habitat}

Gammarus insensibilis was collected from 11 sites (Tab.1, Fig.1), extending latitudinally for ca. $3100 \mathrm{~km}$, ranging from Ria de Aveiro and Sado estuary on the west coast of Portugal, through coastal lagoons of Spain and Morocco, the Italian coasts of the Ionian and Adriatic Seas, the Marmara Sea, to the Black Sea lagoons in Turkey and Bulgaria. Gammarus aequicauda was collected from 36 sites (Tab.1, Fig.1), extending latitudinally for ca. $3000 \mathrm{~km}$, from the lagoons of Mallorca on the west, through the coasts of Sicily, Sardinia, Tunisia, the Adriatic coast of Italy, the Aegean Sea, to the Black Sea lagoons, and the Azov Sea in the east.

\subsection{COI haplotypes: diversity, distribution and divergence}

Out of the 49 individuals of Gammarus insensibilis sequenced, a total of 32 haplotypes was identified. None haplotypes were shared between locations. Localities with highest haplotype diversity were: Black Sea near Istanbul (Site 42 - nine haplotypes), Marmara Sea near Istanbul (Site 41 - four haplotypes), Sozopol Bay in Bulgaria (Site 43 - four haplotypes). Minimum, average and maximum K2p distance between haplotypes were, respectively: 0.002 (SE 0.002), 0.086 (SE 0.009) and 0.161 (SE 0.019).

Out of the 117 individuals of Gammarus aequicauda sequenced, a total of 68 haplotypes was identified. Only five haplotypes were shared between locations (H17 in the Tyrrhenian Sea, H40 in the Black Sea, H42 in the Aegean Sea - two localities; H32 - three localities in the Black Sea; H3 - 13 localities from Black and Azov seas). Each of the remaining 63 haplotypes was specific to only one site. Localities with the highest haplotypes diversity were: Black sea near Odessa (Site 6 - nine haplotypes), Varna Lake (Site 16 - five hapotypes), Burano Lake (Site 26 - five haplotypes), delta of river 
Po (Site 31 - five haplotypes) and S`Albufera on Mallorca (Site 29 - four haplotypes). Minimum, average and maximum K2p distance between haplotypes were, respectively: 0.002 (SE 0.002), 0.075 (SE 0.007) and 0.208 (SE 0.021). The detailed information about the number of specimens within the haplotypes can be found in Table S2.

Such high average K2p distance in both species suggests presence of cryptic diversity within the morphospecies (Table S3, S4). Overall haplotype diversity and nucleotide diversity within clusters remained rather high, with haplotypic diversity ranging from 0.439 to 1 and nucleotide diversity reaching 0.0110 .

\subsection{MOTU delimitation}

All the applied MOTU delimitation methods supported the existence of eight MOTUs within the G. aequicauda morphospecies and four MOTUs within the G. insensibilis morphospecies, with the exception of BINs, which indicated that there is one more MOTU in G. aequicauda group that splits in two the MOTU 2 from the Aegean Sea (Figs. 4,5). Both of the GMYC approaches applied exhibited the same outcome with the same LR test values. The BIN analysis grouped the studied individuals respectively in nine BINs for G. aequicauda, five of which are new to BOLD (BOLD:ADG1589, BOLD:ADB8496, BOLD:ADB8026， BOLD:ACH6172， BOLD:AAD2658, BOLD:ADB8497, BOLD:ADF6157, BOLD:ACY7225, ACY6585) and four for G. insensibilis, all of which are new to BOLD (BOLD:ACY6633, BOLD:AAE6201, BOLD:AAE6168, BOLD:AAD2659). The range of the K2p distance within the morphospecies determined by ABGD was respectively 0.06-0.18 for G. aequicauda and 0.04-0.14 for G. insensibilis. Results of MOTU delimitation methods support high cryptic diversity within both $G$. aequicauda and $G$. insensibilis, as no distinct morphological differences amongst the representatives of respective MOTUs have been found.

\subsection{Diversity and demography within MOTUs}

Analysis of genetic diversity within all the four defined MOTUs (Fig. 2A) of Gammarus insensibilis, and eight MOTUs (Fig. 2B) of Gammarus aequicauda revealed generally a rather high level of haplotypic and nucleotide diversity, as well as of the mean K2p distance that ranged, respectively, from 0.002 to 0.009 and from 0.005 to 0.011 (Table 2). MOTU 3 and MOTU 4 of $G$. insensibilis showed a sign of demographic expansion (Table 2). Results of the BSP analyses showing the temporal 
changes of the effective population size suggests that MOTU 3 (Black and Marmara Sea) experienced rapid population growth that has started ca. 200 thousand years ago, whereas MOTU 4 (central Mediterranean) experienced slow population grow up to 100 thousand years ago, and from that point remained at constant level. Within Gammarus aequicauda only MOTU 3, inhabiting Black and Azov Sea, showed a clear sign of demographic expansion (Table 2), which commenced ca. 200 thousand years ago (Fig. $3)$.

\subsection{Phylogeny reconstruction}

The time-calibrated phylogeny indicated that divergence of both G. aequicauda and G. insensibilis species complexes started already in the late Oligocene/early Miocene (ca. 28-21 million years ago) (Figs. 4,5). The diversification within G. aequicauda morphospecies initiated already at the end of Oligocene or the early beginning of Miocene, between 25-20 million years ago, when the split of MOTU 8 currently inhabiting the Aegean and Black Sea from the rest of the G. aequicauda MOTUs happened (Fig. 4). The MOTU 6 and MOTU 7 inhabiting Tunisian coast split from the others around 12 million years ago (Fig. 4). Afterwards, MOTU 4 from Adriatic Sea and MOTU 5 inhabiting Apennine Peninsula, Sardegna and Mallorca (which along with Tunisian MOTUs 6 and 7 form the western group) diverged around 8 million years ago, whereas the split within the eastern group, between the widespread MOTU 3, present in the Black Sea, MOTU 2 from Greece and Crete, and endemic MOTU 1 from Korfu took place in late Miocene/early Pliocene, ca. 5 million years ago (Fig.4). On the other hand, the divergence within G. insensibilis started in late Miocene, ca. 8 million years ago when MOTU 3 and MOTU 4 inhabiting eastern part of Mediterranean Basin (eastern clade) diverged from two MOTUs 1 and 2 present in the western part of the Basin (western clade). The split within the western clade took place around 2 million years ago, in early Pleistocene (Fig.5).

\section{Discussion}

In the light of recent studies, the cryptic and pseudo-cryptic diversity appears to be a common yet still underexplored phenomenon in numerous animal taxa and largely overlooked in the large scale biodiversity research (Fišer et al., 2018). It has been argued that for it may substantially shift our current perception of species-level 
biodiversity or even that of the speciation processes, the cryptic diversity should be incorporated into evolutionary and ecological studies in order to get a novel insight biodiversity patterns and processes (Fišer et al., 2018). This requires accumulation of evidence across multiple taxa and ecosystems. However, it is already known that the rate of the cryptic diversity detectability is far from homogenous across the species and the habitats (de León and Poulin, 2016), with marine ecosystems being particularly understudied and poorly understood in that matter (Beheregaray and Caccone 2007; Appeltans et al., 2012). Among invertebrates, crustaceans seem to present the highest number of reported cryptic species, nonetheless most of those studies focus on freshwater representatives (de León and Poulin, 2016).

In fresh waters, several studies focused on amphipod crustaceans in Europe, Asia Minor, Middle East and North America and have shown that: 1) most of the widespread and conventionally recognised morphospecies within this group are usually conglomerates of highly divergent lineages with pre-Pleistocene origins that, in many cases, may represent separate cryptic or pseudo-cryptic species (Witt \& Hebert 2000; Katouzian et al. 2016; Mamos et al., 2016; Grabowski et al., 2017) due to their generally limited mobility and lack of airborne or planktonic dispersal stages, amphipods provide an ideal model for studying and understanding evolution of biodiversity patterns in strictly aquatic organisms living in spatially restricted environments such as hydrological networks (Bilton et al., 2001). In contrary, the marine amphipod fauna, already very diverse at the morphological level, has been scarcely surveyed with respect to cryptic diversity, except a few cases of deep-sea and Antarctic morphospecies (France \& Kocher 1996, Baird et al., 2011, Havermans et al., 2011). Few studies have dealt with the coastal amphipods in the Northern Atlantic region showing some limited cryptic diversity in marine/brackishwater Gammarus morphospecies known to be widely distributed along the European and North American Atlantic shores (Kelly et al., 2006; Costa et al., 2009; Krebes et al., 2011).

The study by Kelly et al., (2006) on Gammarus tigrinus along the western Atlantic coast supported the heterogeneity of the species, confirming a clear division between two cryptic species inhabiting respectively the northern and the southern part of the coast. On the other hand, the study on widely distributed, transatlantic species of $G$. duebeni and G. oceanicus, despite the vast distribution, did not exhibit high level of diversity within the studied morphospecies, with COI divergence not exceeding 0.025 
of genetic distance within the morphospecies (Krebes et al., 2011). Similarly low COI genetic distances between geographically distant populations, spanning from Scotland, Wales and German's North Sea, to the south coast of Portugal, have been recorded in Gammarus locusta (0.009 K2p; Costa et al., 2009 and this study; see also Costa et al., 2004, 2005), a very close taxon to our Mediterranean marine Gammarus, which was here used as outgroup. In comparison to these examples with marine/brackishwater Gammarus from elsewhere, our research revealed a high level of cryptic diversity and high lineage divergence, both in Gammarus aequicauda and Gammarus insensibilis at a relatively limited geographic area including the Mediterranean, Black and Azov Seas and the part of eastern Atlantic coast. We have detected eight cryptic lineages for $G$. aequicauda and four cryptic lineages for $G$. insensibilis with the COI divergence within the morphospecies reaching as high as $0.21 \mathrm{~K} 2 \mathrm{p}$ for $G$. aequicauda and 0.16 for $G$. insensibilis. Moreover the haplotypic diversity and the number of detected haplotypes were also relatively high with 68 haplotypes for G. aequicauda and 32 haplotypes for G. insensibilis, compared with 44 for G. tigrinus, 25 for G. oceanicus and 20 for $G$. duebeni. However, the number of haplotypes and thus, the level of cryptic diversity can be affected by the number of analysed individuals (in this study 117 individuals for $G$. aequicauda and 49 for $G$. insensibilis compared to 143 of G. tigrinus, 242 for $G$. oceanicus and 418 for $G$. duebeni from the cited studies). Therefore, the already high level of cryptic diversity observed may be even higher, if the sampling size is larger and the geographic coverage is wider.

Similarly to the study by Costa et al. (2009), our research has also revealed a high level of cryptic diversity and high lineage divergence, both in Gammarus aequicauda and Gammarus insensibilis. Although the material was more limited than in our study, the authors of that study already point out the taxonomic mismatches within those two morphospecies, indicating very similar level of COI divergence to our findings $(0.27$ $\mathrm{K} 2 \mathrm{p}$ for G. aequicauda and $0.15 \mathrm{~K} 2 \mathrm{p}$ in G. insensibilis). Both our study and the study by Costa et al. (2009) line up with the remarks done by Stock in his comprehensive review of G. locusta group (1967), where it is stated that there is a high chance for more, yet undiscovered taxa within these two morphospecies and that further taxonomic work is needed to clarify the true species assignments, which was already confirmed first by genetic data from the previous study (Costa et al., 2009) as well as by the results presented in this study. Among the remaining Gammarus from the "locusta" group 
reported by Stock (1967), COI sequence data is available for Gammarus crinicornis collected on the Atlantic European coast locations, namely Belgium, Portugal (Costa et al., 2009) and the North Sea (Raupach et al., 2015). The type locality of this species is in Netherlands, and the available COI sequences are completely sorted from either $G$. aequicauda and G. insensibilis, forming a MOTU diverging at least $0.22 \mathrm{~K} 2 \mathrm{p}$ from the nearest neighbour (G. aequicauda, MOTUs 6 and 7 are the nearest; data not shown). Hence, the eventuality of $G$. crinicornis be hidden under any of the MOTUs here reported can be discarded. It is noteworthy that, despite the high number of locations sampled in the Mediterranean, we did not find any specimens corresponding to $G$. subtypicus. The type locality is in Banyuls, French Mediterranean coast, and it has been also reported from Mallorca (Spain) and Turkey, both in the Mediterranean and Black Seas' coasts (Stock, 1967). However, this species is not very common (Stock, 1967) and its distribution is probably the worst documented among the marine Mediterranean Gammarus.

Interestingly, the deep divergence of lineages in both studied morphospecies coincides with the major steps in the development of the Mediterranean Sea. In case of $G$. aequicauda the divergence seems to start already in Late Oligocene/Early Miocene when the proto-Mediterranean Basin dissociated from the Tethys Ocean in result of the collision of the African and Euroasiatic continental plates, that caused also the origin of Paratethys, the large epi-continental shallow brackish sea in the north-east, associated with the formation of Alps, Carpathians, Dinarides, Taurus and Elbruz mountains (Rögl, 1999; Bianchi et al., 2012; Goffredo and Dubinsky, 2014). Given the current, very limited distribution of MOTU8 and the time of its divergence, making it the oldest in the G. aequicauda morphogroup, it seems to be a relic lineage that could inhabit the former strait connecting emerging Paratethys with the East Mediterranean Basin, which existed in Early Miocene, but seized to exist in early Middle Miocene (Rögl, 1999; Popov et al., 2004). The remaining G. aequicauda MOTUs presumably diversified from the common ancestor inhabiting Paratethys as the diversification within that group started in late Middle Miocene/Late Miocene, when the connection between Paratethys and the Protomediterranean was re-established (Rögl, 1999; Popov et al., 2004) enabling the possible the colonisation of the current Mediterranean basin, which could eventually lead to split into western (Tyrrhenian, Balearic, Adriatic and south Mediterranean) and eastern (Black, Azow, Aegean and Ionian) lineages of $G$. 
aequicauda. The dominant geological events that could initiate emergence of the presently existing MOTUs within the eastern clade, started with the Messinian Salinity Crisis (approximately 6 MYA). It could have promoted the separation of the Ionian MOTU from those inhabiting the easternmost regions of the Mediterranean. However, the majority of MOTUs, from both the western and the eastern clades, diverged most probably in Pleistocene, what can be associated with the eustatic sea regressions during glacial maxima that have reduced the brackishwater coastal ecosystems to isolated patches, which had a profound effect on evolution and distribution of several aquatic species (i.e. Audzijonyte et al., 2006; Nahavandi et al., 2013). Accordingly, the Black and Azov Sea basin was recurrently isolated from the Mediterranean with several episodes of water intrusions in between (Kerey et al., 2004; Badertscher et al., 2011), which possibly led to the divergence between MOTU 2 and MOTU 3. This pattern holds true also for the reference individuals of $G$. aequicauda from the Caspian Sea, which also belong to the MOTU 3 consisting of the inhabitants of the Black and Azov Sea (Katouzian et al. 2016). This can be explained by the presence of the Pleistocene connection between the Caspian and Black Seas, occurring as recently as 15 thousand years ago (Badertscher et al., 2011).

On the other hand, the divergence of $G$. insensibilis lineages seems to be younger, presumably due to the extinction of some of the ancestral lineages, however similarly to G. aequicauda, is connected with the re-emergence of the connection between Paratethys and the proto-Mediterranean (Rögl, 1999; Popov et al., 2004), which initiated the divergence within $G$. insensibilis. Although the number of lineages is lower than in G. aequicauda, MOTUs can also be similarly divided into western (Alboran, Balearic) and eastern clades (Black, Marmara, Adriatic, Tyrrhenian, Ionian). Accordingly, the diversification within the clades happened probably during sea regressions in Pleistocene, following the pattern in G. aequicauda complex. One of the western lineages, MOTU 2 has migrated through the Strait of Gibraltar, spreading further along the Atlantic coast of Portugal. As G. insensibilis is also known from northern locations at the Atlantic coasts of France and England (Stock 1967), molecular data is needed from these populations to confirm whether these individuals belong to the same lineage as MOTU 2.

The deep history of the extant MOTUs indicates that both G. aequicauda and $G$. insensibilis have survived the mass extinction of marine biota during Messinian Salinity 
Crysis (Bianchi et al., 2012; Goffredo and Dubinsky, 2014). The survival of organisms inhabiting Mediterranean waters, often in remaining coastal refugia, have been confirmed and documented for numerous invertebrate and fish taxa, which are now considered to be the Mediterranean paleoendemics (Tortonese, 1985; Bianchi et al., 2012; Por 2009). It is argued that for species deriving from former Paratethian ancestors, most of which are considered to be euryhaline, it could have been possible to survive either in freshwater and subterranean refugia or the hypersaline lagoons (Bianchi et al., 2004, 2012). It seems like plausible scenario also for G. aequicauda and G. insensibilis lineages, where the majority of MOTUs inhabiting current Mediterranean basin exhibit relatively low haplotypic diversity, which might reflect the bottleneck effect after Messinian Salinity Crisis. Thus, one may argue that even current high cryptic diversity can be merely a remnant of a formerly even higher amount of individual lineages. Concerning the number of haplotypes, the high haplotypic diversity is particularly striking in the MOTUs of both species, currently present in the eastern part of Mediterranean, especially MOTUs 3 of both G. aequicauda and G. insensibilis inhabiting the Pontic region. The star-like shape of haplotype networks and the results of BSP suggest the recent Pleistocene expansion of the eastern populations, which combined with the extraordinary high number of haplotypes might be the result of the fragmentation of the population connected with the water level fluctuations and changes in salinity caused by the numerous water intrusions between Black Sea and Mediterranean and Caspian sea waters (Badertscher et al., 2011).

The present distribution of cryptic lineages within both studied species seems to be geographically structured in result of such a long and dynamic geological history of the Mediterranean. A very interesting feature of this distribution is that, according to our collection data, neither the two species nor the different MOTUs within each species, occur in sympatry. On the morphospecies level, it is not surprising as they are no clear evidence for these species to coexist, except for one case in French coast, which may be the result of their different habitat and salinity preferences (Stock, 1967; Janssen et al., 1979). However, MOTU-wise, such presence of a single MOTU per site may be associated with the impact of monopolization, where combination of rapid population growth and fast adaptation of incoming individuals to local conditions strongly inhibits further colonisation and enhances the priority effect (De Meester et al., 2002). Given the high reproductive success and euryoeciousness of both species, it might provide an 
explanation for their current wide, but single-species and single-MOTU, distribution (Janssen et al., 1979; Kevrekidis et al., 2009). In the only paper focusing on the ecology and sympatric occurrence of these two species (Janssen et al., 1979), the authors argue that G. insensibilis has greater reproductive success than G. aequicauda and that is has a wider distribution over the shared localities. However, they also indicate that the tolerance to changing environmental conditions is higher in $G$. aequicauda than in $G$. insensibilis, which favours the former species in unstable and rapidly changing conditions. Thus, the current distribution of the members of the particular morphospecies in the studied area, apart from possible sampling bias, apparently reveal a succession of phylogeographic footprints that persisted till the present, reflecting the turbulent and rapidly changing history of the Mediterranean Region.

\section{Conclusions}

Our results support a substantial level of cryptic diversity in two widespread marine amphipods inhabiting the Mediterranean region, G. insensibilis and G. aequicauda. Although it confirms the pattern of the genetic heterogeneity of widely distributed marine Mediterranean fauna already reported from other crustaceans (i.e. Deli et al., 2017; Pannacciulli et al., 2017; Weiss et al., 2017) as well as other invertebrates (i.e. Fernández et al., 2015; De Luca et al., 2016; El Ayari et al., 2017), our study provides arguably the first evidence for such high level of cryptic diversity with deep divergence and evolutionary history. Even though it is not as pronounced as in the freshwater congeners (i.e. Mamos et al., 2016; Grabowski et al., 2017; Copilaş-Ciocianu et al., 2017), the number of individual lineages here detected is somewhat unexpected in the marine habitat and more molecular studies on widely distributed circum-Mediterranean marine biota are needed for further evidence.

The phylogenetic history combined with the current geographic distribution indicate that the evolution of both Gammarus morphospecies has been connected with the geological events in the history of the Mediterranean Basin and reflects the shifts of the continental landmasses as well as the shifts in the sea level. However, our results raise the question of the isolation of the lineages and their relatively limited distribution area. The Mediterranean is known to have several major biogeographical barriers like Strait of Gibraltar, Mid-Aegean Trench or Sicilo-Tunisian Strait, but our study suggests that there might be more, yet undescribed, barriers, which may impair the dispersal of some 
marine biota. We also emphasize the great need for further studies on the ecology of the newly discovered lineages to gain more insight into the colonisation and monopolisation patterns. Given the high human impact and climate change in the Mediterranean Region (Bianchi and Morri, 2000) and that amphipods are one of key components in the aquatic food webs (MacNeil et al., 1997), there is a urgent demand for more studies revealing the actual diversity of often overlooked, widely distributed taxa, which could help in planning a reasonable strategy for its protection and conservation.

\section{Acknowledgments}

We would like to thank the colleagues involved in sampling expeditions: Karolina Bącela-Spychalska, Tomasz Mamos, Piotr Gadawski, Aleksandra Bańkowska, Anna Wysocka, Paula Krzywoźniak, Grzegorz Michoński, Magdalena Kłosowska, Tomasz Rek, Andrzej Zawal, Agnieszka Szlauer-Łukaszewska. M. S. Ferreira for assistance with some of the initial molecular work at the University of Minho. We are also thankful to colleagues who kindly provided specimens, namely Jasna Vukič (Charles University, Czech Republic), Radek Šanda (National Museum, Czech Republic), Jan Beermann (Alfred Wegener Institute, Germany), Andrea Desiderato (Universidade Federal do Paraná, Brazil), Sergiy Kudrenko (Institute of Marine Biology, Ukraine) and Victoria Fernandez-Gonzalez (University of Alicante, Spain).

\section{Funding}

This work was supported by Polish National Science Center (projects no. 2014/15/B/NZ8/00266 and 2015/17/N/NZ8/01628) and partially by the statutory funds of the Department of Invertebrate Zoology and Hydrobiology of University of Lodz. F. Costa and the University of Minho contribution was supported by the strategic programme UID/BIA/04050/2013 (POCI-01-0145-FEDER-007569) funded by national funds through the FCT I.P. and by the ERDF through the COMPETE2020 Programa Operacional Competitividade e Internacionalização (POCI). There was no additional external funding received for this study. The funders had no role in study design, data collection and analysis, decision to publish, or preparation of the manuscript. 


\section{References}

Altschul, S.F., Gish, W., Miller, W., Myers, E.W., Lipman, D.J., 1990. Basic local alignment search tool. Journal of Molecular Biology, 215(3), 403-410.

Appeltans, W., Ahyong, S.T., Anderson, G., Angel, M.V., Artois, T., Bailly, N., ... \& Błażewicz-Paszkowycz, M., 2012. The magnitude of global marine species diversity. Current Biology, 22(23), 2189-2202.

Astrin, J.J., Stüben, P.E., 2008. Phylogeny in cryptic weevils: molecules, morphology and new genera of western Palaearctic Cryptorhynchinae (Coleoptera: Curculionidae). Invertebrate Systematics, 22(5), 503-522.

Audzijonyte, A., Daneliya, M.E., Väinölä, R., 2006. Comparative phylogeography of Ponto-Caspian mysid crustaceans: isolation and exchange among dynamic inland sea basins. Molecular Ecology, 15(10), 2969-2984.

Badertscher, S., Fleitmann, D., Cheng, H., Edwards, R.L., Göktürk, O.M., Zumbühl, A., ... \& Tüysüz, O., 2011. Pleistocene water intrusions from the Mediterranean and Caspian seas into the Black Sea. Nature Geoscience, 4(4), 236.

Baird, H.P., Miller, K.J., Stark, J.S., 2011. Evidence of hidden biodiversity, ongoing speciation and diverse patterns of genetic structure in giant Antarctic amphipods. Molecular Ecology, 20(16), 3439-3454.

Beheregaray, L.B., Caccone, A., 2007. Cryptic biodiversity in a changing world. Journal of Biology, 6(4), 9.

Bellan-Santini, D., Karaman, G., Krapp-Schickel, G., Ledoyer, M., Myers, A., Ruffo, S., Schiecke, U., 1982. The Amphipoda of the Mediterranean. Part 1: Gammaridae (Acanthonotozomatidae to Gammaridae). Mémoires de l'Institut Océanographique, Monaco, 13. Institut Océanographique: Monaco. ISBN 2-7260-0133-5. 364 pp.

Bianchi, C.N., Morri, C., 2000. Marine biodiversity of the Mediterranean Sea: situation, problems and prospects for future research. Marine Pollution Bulletin, 40(5), 367-376.

Bianchi, C.N., Boero, F., Fraschetti, S., Morri, C., 2004. The wildlife of the Mediterranean. Wildlife in Italy. Touring Editore, Milan, Italy, 248-335.

Bianchi, C.N., Morri, C., Chiantore, M., Montefalcone, M., Parravicini, V., Rovere, A., 2012. Mediterranean Sea biodiversity between the legacy from the past and a future of 
change. In: Stambler, N., (Ed.) Life in the Mediterranean Sea: a look at habitat changes. Nova Science Publishers, New York, USA, 1-55.

Bilton, D.T., Freeland, J.R., Okamura, B., 2001. Dispersal in freshwater invertebrates. Annual Review of Ecology and Systematics, 32, 159-181.

Bouckaert, R., Heled, J., Kühnert, D., Vaughan, T., Wu, C.H., Xie, D., ... \& Drummond, A.J., 2014. BEAST 2: a software platform for Bayesian evolutionary analysis. PLoS Computational Biology, 10(4), e1003537.

Bouckaert, R.R., Drummond, A.J., 2017. bModelTest: Bayesian phylogenetic site model averaging and model comparison. BMC Evolutionary Biology, 17(1), 42.

Brower, A. V. (1994). Rapid morphological radiation and convergence among races of the butterfly Heliconius erato inferred from patterns of mitochondrial DNA evolution. Proceedings of the National Academy of Sciences, 91(14), 6491-6495.

Cabezas, M.P., Cabezas, P., Machordom, A., Guerra-Garcia, J.M., 2013. Hidden diversity and cryptic speciation refute cosmopolitan distribution in Caprella penantis (Crustacea: Amphipoda: Caprellidae). Journal of Zoological Systematics and Evolutionary Research, 51, 85-99.

Casagranda, C., Mohamed, S., Charles, D., Boudouresque, F., 2006. Abundance, population structure and production of macro-invertebrate shredders in a Mediterranean brackish lagoon, Lake Ichkeul, Tunisia. Estuarine, Coastal and Shelf Science, 66, 437446.

Copilaş-Ciocianu, D., Petrusek, A., 2015. The southwestern Carpathians as an ancient centre of diversity of freshwater gammarid amphipods: insights from the Gammarus fossarum species complex. Molecular Ecology, 24(15), 3980-3992.

Copilaş-Ciocianu, D., Petrusek, A., 2017. Phylogeography of a freshwater crustacean species complex reflects a long-gone archipelago. Journal of Biogeography, 44(2), 421432.

Copilaş-Ciocianu, D., Rutová, T., Pařil, P., Petrusek, A., 2017. Epigean gammarids survived millions of years of severe climatic fluctuations in high latitude refugia throughout the Western Carpathians. Molecular Phylogenetics and Evolution, 112, 218-229. 
Costa, F.O., Correia, A.D., Costa, M.H., 1998. Acute marine sediment toxicity: A potential new test with the amphipod Gammarus locusta. Ecotoxicology and Environment Safety, 40, 81-87.

Costa, F.O., Costa, M.H., 1999. Life history of the amphipod Gammarus locusta in the Sado Estuary (Portugal). Acta Oecologica, 20, 305-314.

Costa F.O., Costa M.H., 2000. Review of the ecology of Gammarus locusta (L.). Polish Archives of Hydrobiology, 48: 541-559.

Costa, F.O., Cunha, M.R., Neuparth, T., Theodorakis, C.W., Helena Costa, M.H., Shugart L.R., 2004. Application of RAPD DNA fingerprinting in taxonomic identification of amphipods: a case-study with Gammarus species (Crustacea: Amphipoda). Marine Ecology Progress Series, 277, 197-207.

Costa, F.O., Neuparth, T., Correia, A.D., Costa, M.H., 2005. Multi-level assessment of chronic toxicity of estuarine sediments with the amphipod Gammarus locusta: II. Organism and population-level endpoints. Marine Environment Research, 60, 93-110.

Costa, F.O., DeWaard, J.R., Boutillier, J., Ratnasingham, S., Dooh, R.T., Hajibabaei, M., Hebert, P.D., 2007. Biological identifications through DNA barcodes: the case of the Crustacea. Canadian Journal of Fisheries and Aquatic Sciences, 64(2), 272-295.

Costa, F.O., Henzler, C.M., Lunt, D.H., Whiteley, N., Rock, J., 2009. Probing marine Gammarus (Amphipoda) taxonomy with DNA barcodes. Systematics \& Biodiversity, 7, 365-379.

Deli, T., Pfaller, M., Schubart, C.D., 2017. Phylogeography of the littoral prawn species Palaemon elegans (Crustacea: Caridea: Palaemonidae) across the Mediterranean Sea unveils disparate patterns of population genetic structure and demographic history in the two sympatric genetic types II and III. Marine Biodiversity, 1-23.

de León, G.P.P., Poulin, R., 2016. Taxonomic distribution of cryptic diversity among metazoans: not so homogeneous after all. Biology Letters, 12(8), 20160371.

De Luca, D., Catanese, G., Procaccini, G., Fiorito, G., 2016. Octopus vulgaris (Cuvier, $1797)$ in the Mediterranean Sea: Genetic diversity and population structure. PloS One, 11(2), e0149496. 
De Meester, L., Gómez, A., Okamura, B., Schwenk, K., 2002. The Monopolization Hypothesis and the dispersal-gene flow paradox in aquatic organisms. Acta Oecologica, 23(3), 121-135.

Drummond, A.J., Rambaut, A., Shapiro, B.E.T.H., Pybus, O.G., 2005. Bayesian coalescent inference of past population dynamics from molecular sequences. Molecular Biology and Evolution, 22(5), 1185-1192.

Drummond, A.J., Suchard, M.A., Xie, D., ,Rambaut, A., 2012. Bayesian phylogenetics with BEAUti and the BEAST 1.7. Molecular Biology and Evolution, 29(8), 1969-1973.

El Ayari, T., Trigui El Menif, N., Saavedra, C., Cordero, D., Viard, F., Bierne, N., 2017. Unexpected mosaic distribution of two hybridizing sibling lineages in the teleplanically dispersing snail Stramonita haemastoma suggests unusual postglacial redistribution or cryptic invasion. Ecology and Evolution, 7(21), 9016-9026.

France, S.C., Kocher, T.D., 1996. Geographic and bathymetric patterns of mitochondrial 16S rRNA sequence divergence among deep-sea amphipods, Eurythenes gryllus. Marine Biology, 126(4), 633-643.

Fernández, R., Lemer, S., McIntyre, E., Giribet, G., 2015. Comparative phylogeography and population genetic structure of three widespread mollusc species in the Mediterranean and near Atlantic. Marine Ecology, 36(3), 701-715.

Fišer, C., Robinson, C.T., Malard, F., 2018. Cryptic species as a window into the paradigm shift of the species concept. Molecular Ecology, 27(3), 613-635.

Folmer, O., Black, M., Hoeh, W., Lutz, R., Vrijenhoek, R., 1994. DNA primers for amplification of mitochondrial cytochrome c oxidase subunit I from diverse metazoan invertebrates. Molecular Marine Biology and Biotechnology, 3, 294-299.

Gerhardt, A., Bloor, M., Mills, L. 2011. Gammarus: important taxon in freshwater and marine changing environments. International Journal of Zoology, vol. 2011, Article ID 524276, 2 pages. doi:10.1155/2011/524276.

Gillil, P.M., Sanderson, W.G., 2000. Re-evaluation of marine benthic species of nature conservation importance: a new perspective on certain "lagoonal specialists" with particular emphasis on Alkmaria romijni Horst (Polychaeta: Ampharetidae). Aquatic Conservation Marine and Freshwater Ecosystems, 10, 1-2. 
Goffredo, S., Dubinsky, Z. (Eds.)., 2013. The Mediterranean Sea: Its history and present challenges. Springer Science \& Business Media.

Grabowski, M., Mamos, T., Bącela-Spychalska, K., Rewicz, T., Wattier, R.A., 2017. Neogene paleogeography provides context for understanding the origin and spatial distribution of cryptic diversity in a widespread Balkan freshwater amphipod. PeerJ, 5, e3016.

Griffiths, H.I., Krystufek, B., Reed, J.M., 2004. Balkan biodiversity. Kluwer Academic Publishers, Dordrecht. doi: 10,978-1.

Havermans, C., Nagy, Z.T., Sonet, G., De Broyer, C., Martin, P., 2011. DNA barcoding reveals new insights into the diversity of Antarctic species of Orchomene sensu lato (Crustacea: Amphipoda: Lysianassoidea). Deep Sea Research Part II: Topical Studies in Oceanography, 58, 230-241.

Hebert, P.D.N., Cywinska, A., Ball, S.L. ,deWaard, J.R., 2003. Biological identifications through DNA barcodes. Proceedings of the Royal Society of London Series B-Biological Sciences, 270, 313-321.

Hillis, D.M., Moritz, C., Mable, B.K., 1996. Molecular systematics. Sinauer Associates. Sunderland, MA, USA.

Hou, Z., Fu, J., Li, S., 2007. A molecular phylogeny of the genus Gammarus (Crustacea: Amphipoda) based on mitochondrial and nuclear gene sequences. Molecular Phylogenetics and Evolution, 45(2), 596-611

Hou, Z., Sket, B., Fišer, C., Li, S., 2011. Eocene habitat shift from saline to freshwater promoted Tethyan amphipod diversification. Proceedings of the National Academy of Sciences, 108(35), 14533-14538.

Hupało, K., Mamos, T., Wrzesińska, W., Grabowski, M., 2018. First endemic freshwater Gammarus from Crete and its evolutionary history-an integrative taxonomy approach. PeerJ, 6, e4457.

Huson, D.H., Bryant, D., 2006. Application of phylogenetic networks in evolutionary studies. Molecular Biology and Evolution, 23(2), 254-267.

ICZN, 1973. Opinion 992. Gammarus aequicauda (Martynov, 1931) (Crustacea: Amphipoda): validated under the plenary powers. Z.N.(S.) 1900. Bulletin of Zoological Nomenclature, 30, 15-16. 
Janssen, H., Scheepmaker, M., van Couwelaar, M., Pinkster, S., 1979. Biology and distribution of Gammarus aequicauda and G. insensibilis (Crustacea, amphipoda) in the lagoon system of Bages-Sigean (France). Bijdragen Tot de Dierkunde, 49, 42-70.

Katouzian, A.R., Sari, A., Macher, J.N., Weiss, M., Saboori, A., Leese, F., Weigand, A.M., 2016. Drastic underestimation of amphipod biodiversity in the endangered IranoAnatolian and Caucasus biodiversity hotspots. Scientific Reports, 6, 22507. DOI: $10.1038 /$ srep 22507.

Kearse, M., Moir, R., Wilson, A., Stones-Havas, S., Cheung, M., Sturrock, S., ... \& Thierer, T., 2012. Geneious Basic: an integrated and extendable desktop software platform for the organization and analysis of sequence data. Bioinformatics, 28(12), 1647-1649.

Kelly, D.W., MacIsaac, H.J., Heath, D.D., 2006. Vicariance and dispersal effects on phylogeographic structure and speciation in a widespread estuarine invertebrate. Evolution, 60(2), 257-267.

Kerey, I.E., Meriç, E., Tunoğlu, C., Kelling, G., Brenner, R.L., Doğan, A.U., 2004. Black Sea-Marmara Sea Quaternary connections: new data from the Bosphorus, Istanbul, Turkey. Palaeogeography, Palaeoclimatology, Palaeoecology, 204(3-4), 277295.

Kevrekidis, C.T., Koukouras, A., 1988. Life cycle and reproduction of Gammarus aequicauda (Crustacea: Amphipoda) in the Evros Delta (NE Greece). Israel Journal of Zoology, 35, 137-149.

Kevrekidis, T., Kourakos, G., Boubonari, T., 2009. Life history, reproduction, growth, population dynamics and production of Gammarus aequicauda (Crustacea: Amphipoda) at extremely low salinities in a mediterranean lagoon. International Review of Hydrobiology, 94, 308-325. https://doi.org/10.1002/iroh.200811097

Kinne, O., 1954. Die Gammarus-Arten der Kieler Butch. Zoologische Jahrbuecher Abteilung fuer Systematik Oekologie und Geographie der Tiere, 82, 405-424.

Knox, M.A., Hogg, J.D., Pilditch, C.A., 2011. The role of vicariance and dispersal on New Zealand's estuarine biodiversity: the case of Paracorophium (Crustacea: Amphipoda). Biological Journal of the Linnean Society, 103, 863-874. 
Krebes, L., Blank, M., Bastrop, R., 2011. Phylogeography, historical demography and postglacial colonization routes of two amphi-Atlantic distributed amphipods. Systematics and Biodiversity, 9(3), 259-273.

Kumar, S., Stecher, G., Tamura, K., 2016. MEGA7: Molecular Evolutionary Genetics Analysis version 7.0 for bigger datasets. Molecular Biology and Evolution, 33(7), 1870-1874.

Leigh, J.W., Bryant, D., 2015. PopART: full-feature software for haplotype network construction. Methods in Ecology and Evolution, 6(9), 1110-1116

Librado, P., Rozas, J., 2009. DnaSP v5: a software for comprehensive analysis of DNA polymorphism data. Bioinformatics, 25(11), 1451-1452.

Lincoln, R.J., 1979. British marine amphipoda: Gammaridea. British Museum (Natural History), London.

Lobo, J., Ferreira, M.S, Antunes, I.C., Teixeira, M.A.L., Borges, L.M.S., Sousa, R., Gomes, P.A., Costa M.H., Cunha, M.R., Costa, F.O., 2017. Contrasting morphological and DNA barcode-suggested species boundaries among shallow-water amphipod fauna from the southern European Atlantic coast. Genome, 60, 147-157.

Lörz, A-N., Smith, P., Linse, K., Steinke, D., 2012. High genetic diversity within Epimeria georgiana (Amphipoda) from the southern Scotia Arc. Marine Biodiversity 42: $137-159$.

MacDonald III, K. S., L. Yampolsky ,J. Duffy, 2005. Molecular and morphological evolution of the amphipod radiation of Lake Baikal. Molecular Phylogenetics and Evolution, 35, 323-343.

MacNeil, C., Dick, J.T., Elwood, R.W., 1997. The trophic ecology of freshwater Gammarus spp.(Crustacea: Amphipoda): problems and perspectives concerning the functional feeding group concept. Biological Reviews, 72(3), 349-364.

MacNeil, C., Dick, J., Elwood, R., 1999. The dynamics of predation on Gammarus spp. (Crustacea: Amphipoda). Biological Reviews, 74, 375-395.

Mamos, T., Wattier, R., Majda, A., Sket, B., Grabowski, M., 2014. Morphological vs. molecular delineation of taxa across montane regions in Europe: the case study of Gammarus balcanicus Schäferna (Crustacea: Amphipoda). Journal of Zoological Systematics and Evolutionary Research, 52(3), 237-248. 
Mamos, T., Wattier, R., Burzyński, A., Grabowski, M., 2016. The legacy of a vanished sea: a high level of diversification within a European freshwater amphipod species complex driven by 15 My of Paratethys regression. Molecular Ecology, 25(3), 795810.

Monaghan, M.T., Wild, R., Elliot, M., Fujisawa, T., Balke, M., Inward, D.J., ... \& Vogler, A.P., 2009. Accelerated species inventory on Madagascar using coalescentbased models of species delineation. Systematic Biology, 58(3), 298-311.

Myers, A.A., 1982. Family Corophiidae. - In: RUFFO S. (ed). - The Amphipoda of the Mediterranean. Part 1. Gammaridea. - Mémoires de l'Institut Océanographique, Monaco, 13, 185-208.

Nahavandi, N., Ketmaier, V., Plath, M., Tiedemann, R., 2013. Diversification of PontoCaspian aquatic fauna: Morphology and molecules retrieve congruent evolutionary relationships in Pontogammarus maeoticus (Amphipoda: Pontogammaridae). Molecular Phylogenetics and Evolution, 69(3), 1063-1076.

Neuparth, T., Correia A.D., Costa, F.O., Lima, G., Costa, M.H., 2005. Multi-level assessment of chronic toxicity of estuarine sediments with the amphipod Gammarus locusta: I. Biochemical endpoints. Marine Environmental Research, 60, 69-91.

Nisancioglu, KH., 2010. Plio-pleistocene glacial cycles and milankovitch variability. In: Steele JH, Turekian, KK., Thorpe, SA. (Eds.)., Encyclopedia of Ocean Sciences. London: Academic Press. 504-513

Palumbi, S.R., Martin, A., Romano, S., McMillan, W. O., Stice, L., Grabowski, G., 1991. The Simple Fool's Guide to PCR. Special publication Department of Zoology and Kewalo Marine Laboratory, University of Hawaii.

Pannacciulli, F.G., Maltagliati, F., De Guttry, C., Achituv, Y., 2017. Phylogeography on the rocks: The contribution of current and historical factors in shaping the genetic structure of Chthamalus montagui (Crustacea, Cirripedia). PloS One, 12(6), e0178287. Pons, J., Barraclough, T.G., Gomez-Zurita, J., Cardoso, A., Duran, D.P., Hazell, S., ... \& Vogler, A.P., 2006. Sequence-based species delimitation for the DNA taxonomy of undescribed insects. Systematic Biology, 55(4), 595-609. 
Popov, S.V., Rögl, F., Rozanov, A.Y., Steiniger, F.F., Shcherba, I.G., Kovac, M., 2004. Lithological-Paleogeographic maps of Paratethys: 10 maps Late Eocene to Pliocene. Courier Forschunginstitut Senckenberg, 250, 1-46.

Por, F.D., 2009. Tethys returns to the Mediterranean: success and limits of tropical recolonization. Biodiversity and Ecosystem Risk Assessment, 3, 5-19.

Prato, E., Biandolino, F., 2003. Seasonal changes in population of the Amphipod Gammarus aequicauda (Martynov, 1931). Mediterranean Marine Science, 4, 49-56. https://doi.org/10.12681/mms.240

Prato, E., Biandolino, F., 2005. Gammarus aequicauda (Crustacea: Amphipoda): A potential test species in marine sediment toxicity assessment, Aquatic Ecosystem Health Management, 8, 475-482.

Puillandre, N., Lambert, A., Brouillet, S., Achaz, G., 2012. ABGD, Automatic Barcode Gap Discovery for primary species delimitation. Molecular Ecology, 21(8), 1864-1877.

Radulovici, A.E., Sainte-Marie, B., Dufresne, F., 2009. DNA barcoding of marine crustaceans from the Estuary and Gulf of St Lawrence: a regional-scale approach. Molecular Ecology, 9, 181-187.

Ratnasingham, S., Hebert, P.D., 2007. BOLD: The Barcode of Life Data System (http://www. barcodinglife.org). Molecular Ecology Resources, 7(3), 355-364.

Ratnasingham, S.,Hebert, P.D., 2013. A DNA-based registry for all animal species: the Barcode Index Number (BIN) system. PloS One, 8(7), e66213.

Raupach, M.J., Barco, A., Steinke, D., Beermann, J., Laakmann, S., Mohrbeck, I., Neumann, H., Kihara, T.C., Pointner, K., Radulovici, A., Segelken-Voigt, A., Wesse, C., and Knebelsberger, T., 2015. The application of DNA barcodes for the identification of marine crustaceans from the North Sea and adjacent regions. PLoS One, 10, e0139421.

Remy, F., Collard, F., Gilbert, B., Compere, P., Eppe, G., Lepoint, G., 2015. When microplastic is not plastic: the ingestion of artificial cellulose fibers by macrofauna living in seagrass macrophytodetritus. Environmental Science \& Technology, 49, 11158-11166. https://doi.org/10.1021/acs.est.5b02005.

Rögl, F., 1999. Mediterranean and Paratethys. Facts and hypotheses of an Oligocene to Miocene paleogeography (short overview). Geologica Carpathica, 50(4), 339-349. 
Ryer, C.H., 1988. Pipefish foraging: effects of fish size, prey size and altered habitat complexity. Marine Ecology Progress Series, 48, 37-45.

Segerstråle, S.G., 1947. New observations on the distribution and morphology of the amphipod Gammarus zaddachi Sexton with notes on related species. Journal of the Marine Biological Association of the United Kingdom, 27, 219-244.

Selkoe, K.A., D’Aloia, C.C., Crandall, E.D., Iacchei, M., Liggins, L., Puritz, J.B., von der Heyden, S., Toonen, R.J., 2016. A decade of seascape genetics: contributions to basic and applied marine connectivity. Marine Ecology Progress Series, 554, 1-19.

Seutin, G., White, B.N., Boag, P.T., 1991. Preservation of avian blood and tissue samples for DNA analyses. Canadian Journal of Zoology, 69(1), 82-90.

Spooner, G.M., 1947. The distribution of Gammarus species in estuaries. Part I. Journal of the Marine Biological Association of the United Kingdom, 27, 1-52.

Stock, J.H., 1967. A revision of the European species of the Gammarus locusta-group (Crustacea, Amphipoda). Zoologische Verhandelingen, 90, 1-56.

Stock, J.H., 1969. Essais d'hybridisation entre Gammarus aequicauda (Martynov, 1931) et Gammarus plumicornis Costa, 1853. Bulletin Zoölogisch Museum Universiteit van Amsterdam, 1, 153-156.

Stock, J.H., 1970. Gammarus aequicauda (Martynov, 1931) (Crustacea: Amphipoda): a request for preservation under the plenary powers. Z.N.(S.) 1900. Bulletin of Zoological Nomenclature, 27, 49-50.

Tamura, K., Nei, M., 1993. Estimation of the number of nucleotide substitutions in the control region of mitochondrial DNA in humans and chimpanzees. Molecular Biology and Evolution, 10(3), 512-526.

Thiel, M., Reise K., 1993. Interaction of nemertines and their prey on tidal flats, Netherlands Journal of Sea Research, 31, 163-172, https://doi.org/10.1016/00777579(93)90006-E

Tortonese, E., 1985. Distribution and ecology of endemic elements in the Mediterranean fauna (fishes and echinoderms). In: Mediterranean marine ecosystems (pp. 57-83). Springer, Boston, MA. 
Verkuil, Y., Koolhaas, A., van der Winden, J., 1993. Wind effects on prey availability: How northward migrating waders use brackish and hypersaline lagoons in the sivash, Ukraine, Netherlands Journal of Sea Research, 31, 359-374. https://doi.org/10.1016/0077-7579(93)90053-U.

Weiss, M., Macher, J.N., Seefeldt, M.A., Leese, F., 2014. Molecular evidence for further overlooked species within the Gammarus fossarum complex (Crustacea: Amphipoda). Hydrobiologia, 721(1), 165-184.

Weiss, R., Torrecilla, Z., González-Ortegón, E., González-Tizón, A.M., MartínezLage, A., Schubart, C.D., 2017. Genetic differentiation between Mediterranean and Atlantic populations of the common prawn Palaemon serratus (Crustacea: Palaemonidae) reveals uncommon phylogeographic break. Journal of the Marine Biological Association of the United Kingdom, 98(6), 1425-1434.

Witt, J.D., Hebert, P.D.N., 2000. Cryptic species diversity and evolution in the amphipod genus Hyalella within central glaciated North America: a molecular phylogenetic approach. Canadian Journal of Fisheries and Aquatic Sciences, 57(4), 687-698.

Wysocka, A., Grabowski, M., Sworobowicz, L., Mamos, T., Burzyński, A., Sell, J., 2014. Origin of the Lake Ohrid gammarid species flock: ancient local phylogenetic lineage diversification. Journal of Biogeography, 41, 1758-1768.

Yang, L., Hou, Z., Li, S., 2013. Marine incursion into East Asia: a forgotten driving force of biodiversity. Proceedings of the Royal Society B: Biological Sciences, 280, 20122892.

Zhang, J., Kapli, P., Pavlidis, P., ,Stamatakis, A., 2013. A general species delimitation method with applications to phylogenetic placements. Bioinformatics, 29(22), 286.

\section{Figure captions}

Fig.1 Map of the sampling sites in the Mediterranean and the Pontic Region. The dots indicate the sites and the colours represent the associated colours of the respective MOTUs of Gammarus aequicauda and G. insensibilis. Two-letter abbreviations represent the respective sea basins: AT-Atlantic, AL-Alboran, BA-Balearic, TYTyrrhenian, SM-South Mediterranean, AD-Adriatic, IO-Ionian, AG-Aegean, MAMarmara, BL-Black, AZ-Azov. 
Fig.2 The phylogenetic network computed with the neighbour-net algorithm and uncorrected p-distances with the Minimum Spanning Networks for the respective MOTUs. The colours correspond to those presented in other figures. A) Gammarus insensibilis, B) Gammarus aequicauda.

Fig.3 Bayesian Skyline Plots for selected MOTUs of G. aequicauda and G. insensibilis. Fig.4 Maximum clade credibility, time-calibrated Bayesian reconstruction of phylogeny of the Gammarus aequicauda species complex. Phylogeny was inferred from a sequences of the mitochondrial COI and 16S rRNA genes and nuclear 28S rRNA gene. The numbers by respective nodes indicate Bayesian posterior probability values $\geq 0.95$. Black bars indicate the respective MOTUs of Gammarus morphospecies, with the coloured ones representing ABGD delimitation method and violet node bars represent 95\% HPD.

Fig.5 Maximum clade credibility, time-calibrated Bayesian reconstruction of phylogeny of the Gammarus insensibilis species complex. Phylogeny was inferred from a sequences of the mitochondrial COI and 16S rRNA genes and nuclear 28S rRNA gene. The numbers by respective nodes indicate Bayesian posterior probability values $\geq 0.95$. Black bars indicate the respective MOTUs of Gammarus morphospecies, with the coloured ones representing ABGD delimitation method and violet node bars represent 95\% HPD.

Tab.1 Collection sites, MOTUs, haplotypes and accession numbers for specimens of Gammarus used in this study.

Tab.2 Molecular genetic diversity, divergence and historical demography based on mtDNA COI haplotypes for each of the MOTUs detected within Gammarus insensibilis and G. aequicauda. Locations, see Table 1 and Fig. 1 for details about locations. N, sample size. Diversity: $\mathrm{k}$, number of haplotypes, $\mathrm{h}$ and $\pi$, haplotype and nucleotide diversity, respectively. Divergence: K2p, mean Kimura 2-parameter genetic distance between haplotypes within a given MOTU. Demography: D, Tajima's D; Fs, Fu's Fs tests; SSD, sum of squared deviations; r, Harpending's raggedness index .

Tab.S1 Used molecular markers with the primer sequences, PCR cycling conditions and the original references.

Tab.S2 Number of individuals per haplotype per MOTU for both Gammarus morphospecies. 
Tab.S3 Mean Kimura two parameters (K2p) distances (below the diagonal) and standard error (SE) (above the diagonal) between MOTUs for 32 COI haplotypes of Gammarus insensibilis. $\mathrm{N}$ and $\mathrm{k}=$ number of individual sampled and haplotypes per MOTU, respectively.

Tab.S4 Mean Kimura two parameters (K2p) distances (below the diagonal) and standard error (SE) (above the diagonal) between MOTUs for 67 COI haplotypes of Gammarus aequicauda. $\mathrm{N}$ and $\mathrm{k}=$ number of individual sampled and haplotypes per MOTU, respectively. 